Ustymenko A. M.

\title{
CELL TECHNOLOGIES IN TREATMENT OF HUMAN INTERVERTEBRAL DISK HERNIA: PERSPECTIVES
}

\section{ABSTRACT}

The intervertebral disc hernia is distinguished one of the diseases of the human locomotor apparatus that causes pain, neurological deficit and functional disorders.

Inefficency of concervative treatment and repeated appeals for medical help after surgery have urged on the need for exploration of some new more effective methods of treatment aimed not only at weakening degenerative processes and pain but also at renewing disc function and its height maintenance. Achievements of regenerative medicine and tissue engineering promote development of new efficient methods of cell therapy. The results of their application in experimental studies on animals give us hope for their successful use in humans.

KEYWORDS: intervertebral disc, nucleus pulposus, annulus fibrosus, mesenchymal stem cells, cell therapy

Annually, nearly 100 billion dollars are spent for low back pain treatment in the developed countries [1-3]. These costs are allocated not only for medical health care services but also for disability payments in the social provision system.

As a rule, low back pains are linked with degenerative processes in the locomotor apparatus. According to the MRT data, the spinal pains in approximately $40 \%$ of patients are caused by degenerative changes in the intervertebral disc (IVD). These processes are accompanied with higher production of the inflammatory cytokines by the IVD cells. So, the tumor necrosis factor alpha (TNF- $\alpha$ ), interleukine- $1 \alpha / \beta$ and interleukine-17 cause matrix degradation, production of chemokines and change of cell phenotype. This, in turn, leads to the imbalance of catabolic and anabolic processes and to IVD microstructure disturbances like the appearance of cracks and protrusions becoming more marked with time and disrupture of annulus fibrosus (AF) and hernia form appearance in it. It has been shown that appearance of hernias parallels $C D 68^{+}$disc tissue infiltration by the macrophages, neutrophils and T-lymphocytes $\left(\mathrm{CD} 4^{+}, \mathrm{CD}^{+}\right)$, and appearance within IVD structures of nerve fibers-derivatives of the cerebrospinal ganglia $[4,5]$. Under such conditions, the disc and immune cells produce neurogenic factors such as nerve growth factor (NGF) and brain-derived neurotrophic factor (BDNF) that cause pain via influence on the cation channels in the cerebrospinal ganglia [6-8].

Since the physiotherapeutic measures and anesthesia produce only a short-term weakening of pain symptoms, the patients are advised surgical back pain treatment. However even surgery does not guarantee full recovery because after removal of sequestered disc hernia and disappearance of acute neurologic symptomatics there develop irreversible involutive processes in the IVD. They lead to a significant diminution of the disc height that, in its turn, again causes a development of the root syndrome and frequent recurrence ( $15 \%$ ) of hernias after their removal [9-12]. Removal of the nucleus pulposus (NP) tissue during discectomy, irrespective of patient's age, accelerates the process of IVD degeneration $[13,14]$. Furthermore, there may take place limitation of movement and spine biomechanic after spine surgery [15].

Experimental investigations in the biology of stem cells and tissue engineering carried on animals give us hope for the application of cell technologies allowing homeostasis recovery in the degenerative changed human disc [16]. Selection of proper source of cells is the necessary condition for successful transplantation, survival and development of the required quality tissue, especially against a background of changed microenvironment of the degenerative disc. With the view of regenerating and preventing disc height loss at IVD hernias, studies were carried on regenerative potential of the autologous cells of the nucleus pulposus and annulus fibrosus. A special attention has been given to the use of multipotent mesenchymal stromal cells (MMSCs) [17, 18]. Elaboration of new approaches to IVD restoration must be based on the knowledge of its anatomic and histologic structure.

\section{STRUCTURE OF INTERVERTEBRAL DISC}

Human spine has 24 movable discs: 7 cervical (neck), 12 thoracic (chest) and 5 lumbar (back). Except the $1^{\text {st }}$ and $2^{\text {nd }}$ neck discs, all discs are connected by type of symphysis by special structure, the intervertebral disc, which provides for the maintenance of discs together, transmits load, arising from body weight/muscle activity and permits a range of spinal movement (bending, flexion, torsion). The IVD is the fibrocartilaginous structure with three zones: nucleus pulposus, annulus fibrosus and two cartilaginous endplate (CEP).

\section{NUCLEUS PULPOSUS (NP)}

Owing to the NP the hydraulic pressure is uniformly spread to all directions inside each disc under spinal compression load. NP is the highly hydrated (70-90\% depending on age), visco-elastic structure being 
formed mainly by the network of type II collagen fibres (55-65\% dry weight) and a smaller number of type III, VI, IX and XI collagens and proteoglycans. It contains elastin and laminins [19].

Among the proteoglycans (aggrecan, biglycan, decorin and versikan) affording visco-elasticity of the NP, it is worth to set off the aggrecan - a large molecule $\left(3 \cdot 10^{2}-7 \cdot 10^{3} \mathrm{kD}\right)$, an integral part of which is the glycosaminoglycans chains of chondroitine sulphate and keratan sulphate. In the process of non-covalent binding with hyaluronan molecule via connecting protein, the aggrecan forms big negatively charged aggregates, which adsorb and keep water in the NP [20]. Noteworthy, the number of proteoglycans and their ability to keep water inside the NP is diminishing with age [21]. This leads to diminution of the hydrostatic pressure and further loss of disc height and increase of load compressive tension on the AF. As a result, there can appear both protrusions on the AF with a formation of the so-called «Schmorl's nodes», AF disrupture and herniation [22].

Of special attention is the NP cell content. The NP tissue contains heterogeneous population of cells whose composition and morphology undergo changes with age [23]. In adult humans the density of cells is very low making $2 \cdot 10^{3}-5 \cdot 10^{3}$ cells $/ \mathrm{cm}^{3}$ [24]. The extracellular matrix, unique by its composition, is produced mainly by the chondrocyte-like cells and maintained by the population of NP cells, which has a notochordal origin by its phenotypic markers (expression of cytoceratins 8 , 18,19 and galectin-3) [25-29]. It is thought that notochordal cells are specific cells-organizers which stimulate migration of resident stem cells from IVD niches to the NP as well as take part in the maintenance of its homeostasis. The soluble factors secreted by these cells protect NP cells from matrix degradation and apoptosis by inhibiting activities of caspases and metalloproteinases [28].

At human birth the NP cells are large $(25-85 \mu \mathrm{m})$, vacuolized and morphologically resemble embryonal notochordal cells [28]. Across the first years of life they decrease in number and are replaced by small chondrocyte-like cells of the non-notochondral origin [31,32] and for this reason the self-renewing ability of this structure is considerably reduced. The NP is an avascular structure; and in the absence of oxygen the cells survive at the cost of energy obtained by anaerobic glycolysis. Physiological load on the spine stimulates the mechanoreceptors of NP cells, thereby stimulating synthesis of cytokines of the TGF- $\beta$ superfamily. These growth factors regulate anabolic processes in the cartilage tissue of the IVD that activates type II collagen and aggrecan biosynthesis in the NP [33].

\section{ANNULUS FIBROSUS}

AF has a mesenchymal origin [30] and its structure is presented by fibre cartilage tissue, in which the collagen fiber bunches are placed in layers and rings, have various orientation to the disc axis and adjacent plates that give it elasticity during compression. $\mathrm{AF}$ consists of collagens, predominantly type I, (50-70\% of dry weight), proteoglycans (10- $20 \%$ of dry weight), water (60-70\%) and non-collagenous proteins (elastin). Arbitrarily, it is possible to single out the outer and inner zones within this structure. Cell composition and types of collagen synthesized in the above-listed zones differ. The outer zone of AF contains the fibroblast like cells synthesizing type I collagen and a small amount of the capillaries. Type II collagen as well as types III, IV, IX and X are synthesized by the chondrocytes of the inner AF zone to form complex intercellular substance of the AF [19]. Chondrocytes of the intermittent and inner zones, located in the lacunes surrounded by the pericellular matrix, synthesize not only the collagen but also proteoglycans (aggrecan, biglycan, decorin and versikan). Some of the annulus fibers on the periphery penetrate into vertebral bodies, as «sharpey's fibers» [33].

Owing to the specifics of architectonic of AF collagen fibers the relatively stable NP volume is ensured. It should be noted that internal part of the annulus fibrosus is more resistant to high hydrostatic pressure from the nucleus pulposus than to extension efforts of the external part of the AF. Having this in mind, the synthesis of extracellular matrix and its renewal proceeds differently in the various zones: from internal to external zone the synthesis of type I collagen is intensive while that of type II collagen, on the contrary, is reduced. Decorin and biglican are placed mainly in the external part of the AF and type $\mathrm{X}$ collagen in the inner zone. Despite a very small content of the elastin (nearly $2 \%$ of dry weight), it plays an important role in the amortization properties of the AF. Owing to the elastic fibers which are found in all disc components, the dynamic loads are distributed on the intervertebral disc.

In the adults the density of cells in the AF makes about $9 \cdot 10^{6}$ cells $/ \mathrm{cm}^{3}$ that is almost 2 times as greater in comparison with the NP [34]. The study of the cells obtained from human AF has shown their ability for differentiation in the chondrogenic and adipogenic directions $[35,36]$ that gives us the hope for their application at such pathological conditions as IVD hernia.

\section{CARTILAGINOUS ENDPLATES}

Two cartilaginous endplates (CEP) of less than $1 \mathrm{~mm}$ thick lock the disc axially and fit closely to the adjacent vertebral bodies, ensuring diffusion of nutrients and oxygen to the avascular intervertebral disc structures [37]. The CEP is the most vulnerable structure to constant compression forces that can lead to the appearance and accumulation of micro damages (cracks). Under significant forces the AF penetrates into sponge vertebral body and forms Schmorl's hernias [38]. CEP calcification also enhances disc degeneration due to reduced diffusion of both nutrients and by-side products of cell viability. Many authors assume the presence of the niches of progenitor cells in the CEP migrating to the disc $[39,40]$.

It is noteworthy that all elements of the IVD (nucleus pulposus, annulus fibrosus and cartilaginous endplates) are structurally interlinked, and changes, occurring in one of them, lead to the development of negative events within a whole structure. To explain the cause-and-effect relationships of these events as well as to introduce new methods of treatment, using the stem cells in particular, can be possible due to modeling pathological conditions of the locomotor apparatus in animals.

\section{EXPERIMENTAL MODELS OF IVD PATHOLOGIES IN ANIMALS}

Generally, methods of locomotor apparatus treatment using cell technologies have been studied both in small (mice, rats) and big (rabbits, dogs, pigs, goats) animals by modeling degenerative processes through traumatic or chemical impacts on the IVD structures [41-46]. Studies of the regenerative potential of the MSCs, obtained from the adipose-derived tissue, bone marrow and synovial tissue of the knee joint, have shown their ability to gain NP function after transplantation or promote stimulation of the IVD cells to develop extracellular matrix [47]. The above-mentioned effects have been confirmed by radiographic analysis of the disc height, detection of type II collagen and proteoglicans by histological and gene expression analysis. In particular, it has been shown in rabbit experiments that the chondrocytes of elastic cartilage of the rabbit ear introduced into the IVD survive and promote extracellular matrix production and type II synthesis in the NP; chondrocytes of the joint cartilage transplanted into the pig IVD also showed positive effects [48].

There is no ideal model that could be fully identical to the pathological state of human IVD due to several reasons. Firstly, unlike human studies, the experiments include animals with healthy IVD with normal cell composition and microenvironment. Secondly, there are differences in the size of cells and in the composition of NP cell populations (for instance, adult animal NP has notochordal cells which, as a rule, are absent in adult human IVD). In addition, they differ by their biomechanical properties (for example, upright walking of humans) [49-51].

The dog in the most proper animal showing development of spontaneous IVD degeneration accompanied with pain and neurological deficit similarly to such processes in humans [52-55]. It is precisely the dogs that showed the results of effective application of the autologous cells of the IVD cultured in vitro. There are evidences indicating that cells implanted into canine IVD were viable (after BrdU-stain), promoted synthesis of extracellular matrix components similar to IVD composition in the norm. Their proliferative activity has been confirmed histologically [55]. 
Nevertheless, despite difficulties of extrapolation of the results obtained in animals the use of MSCs opens vistas for treatment of IVD hernias and disc degenerative diseases occurring in humans [56].

In the humans there are numerous potential sources of stem cells for their potential use in cell therapy: bone marrow, adipose-derived stem cells (ADSCs) and other tissues (i.e. knee joint synovial tissue, etc.). A great interest has been shown to the study of effectiveness of cells obtained from the IVD (NP cells culture or NP and AF cells co-culture) [57, 58].

Many evidences indicate that human MSCs are capable to differentiate into NP cells and produce matrix containing the proteoglycans and type II collagen. Moreover, co-culture of human MSCs and NP not only enhances differentiation of NP cells but also restores their normal functioning and enhances proliferation. Thus Blanco JF, et al. identified the population of $\mathrm{CD} 105^{+} \mathrm{CD} 73^{+} \mathrm{CD} 90^{+} \mathrm{CD} 45^{-} \mathrm{CD} 34^{-} \mathrm{CD} 14^{-} \mathrm{CD} 11 \mathrm{~b}^{-} \mathrm{CD} 79^{-} \mathrm{CD} 19^{-}$ HLA-DR cells resembling MSCs of the bone marrow, which met minimal criteria of such type of cells developed by the International Society for Cellular Therapy (ISCT) [59].

To enhance regenerative properties of transplanted cells in the zone of damaged disc, the scaffolds of various origins as a three-dimensional matrix for cells has been successfully used. They can support mechanical loads and prevent implanted MSCs population into other tissues, as well as promote proliferation and differentiation. The use is more often made of the hydrogels based on the hyaluronic acid collagen as they are hydrophilic polymers, which are slowly dissolved allowing transplanted MSCs differentiate and produce their own matrix [60]. For survivorship of the transplanted MSCs the scaffolds must be non-immunogenic, bioavailable, biodegradable and bear mechanical loads in the IVD. Owing to its structure the scaffold itself can promote cell differentiation. In particular, the ADSCs introduced into the chitosan-alginate gel are capable to differentiate into nucleus pulposus-like cells at hypoxia [61].

\section{CELL THERAPY OF IVD HERNIA IN CLINIC}

For successful use in clinical practice, the material must be safe and accessible in the maximal amount for regeneration of the IVD structures. Autologous cells are thought to be the safest material. Due to immunoselection it became possible to use cell material of the allogeneic origin. It is very essential to consider the suitability of the phenotype of implanted cells to functioning cells of the disc as well as the way of their introduction and their amount. It is known that the number of introduced cells is critical for their survival. Serigano K., et al. (2010) have shown that the optimal number of autologous MSCs isolated from the iliac crest for transplantation into canine IVD made $10^{6}$ per disc and $10^{7}$ cells - induced apoptosis [62].

To minimize risk of immunogenic reactions and to recover appropriate biological matrix for normal metabolism and biomechanics of the disc, it is desirable to use the autologous cells of the IVD obtained after the removal of hernia sequester.

Such approach was realized by the research group of $\mathrm{H}$. J. Meisel in 2008 who initiated the first randomized trial in humans to evaluate the effectiveness of autologous chondrocytes isolated from hernia sequester (Euro Disc Randomized Trial) [56]. The cell preparation obtained according to the GMP had nearly $5 \cdot 10^{6}$ alive cells. Injection was performed with a thin needle for minimal injury of the AF, as it is known that the size of AF injury correlates with intensified degeneration of the IVD [63-66]. After two-year follow-up the patients demonstrated improvements showing effects that had been obtained earlier in the dogs, namely: pain disappearance, disc height maintenance in comparison with patients without implantation of cell material after hernia removal [56]. It should be stressed that NP cells obtained from patients with disc hernia showed the signs of apoptosis and aging and they produced less type II collagen. Moreover, the authors observed an increased expression of catabolic factors and reduced synthesis of matrix components $[67,68]$. Human NP cells obtained after removal hernia sequester displayed the signs of aging in the culture in vitro, increasing in the number from $19.8 \%$ to $23.9 \%$ at passages 4 and 5 , respectively. This fact is confirmed by the expression of $\beta$-galactosamine (SA $\beta$ Gal) - the marker of cell aging. However, even in such material one could observe the expression of the markers of multipotency 0ct3/4, Notch1 and such markers of MSCs as CD105, CD90 and Stro-1 that evidenced for the presence of primitive cell population in the degenerated disc, which is involved in its regeneration [69].

Since 2012 there has been carried on a new clinical trial (NCT01640457) of a cell preparation called NOVOCART ${ }^{\circledR}$ Disc Plus (Tetec, Germany) obtained from the cells of removed human IVD hernia sequester [70]. Expected results will allow to assess safety and effectiveness of cell therapy in IVD regeneration.

Another source of stem cells is the bone marrow. Interesting results on the use of earlier cultivated autologous bone marrow MSCs were also obtained in the clinical trials carried on the patients with degenerated disc with stable spinal pain symptoms. Orozco L., et al. (2011) injected pre-cultured autologous bone marrow cells straightly into the NP [71] while Yoshikawa T., et al. (2010) performed such injections on the collagen scaffold [72]. In the first case the pain disappeared in 10 patients with intact $\mathrm{AF}$ and stable spinal pain three months post cells injection and disc height increase was seen after 12 months. Such analgesic effect can be explained by improvement of intercellular interactions within the IVD structures manifesting itself prior to tissue regeneration. It can be assumed that injected MSCs in this case manifest immune-modulatory properties. The data of second investigation demonstrate health condition improvement in 2 patients with «vacuum-phenomenon» (presence of gas bubbles of various size inside the disc) confirmed by the X-ray pattern and magnetic resonance imaging. In both patients the authors reported a pain relief and a high-intensity signal in the intervertebral discs after transplantation of MSCs into the zones with collagen sponge that indicated high humidity level for disc height maintenance [72].

There are exceptions among positive results of cell therapy, and therefore proper choice of the source of cells and their number is very important. The investigations of Haufe S. M. and Mark A. R. carried out in 2006 with the use of autologous hematopoietic stem cells isolated from the hipbone showed no improvement in 10 patients with stable disc pain. There may be two reasons for this: a small number of cells obtained in vitro or an improper selection of the cell source, although their previous studies in animals showed positive results [73].

Owing to the immunoselection it became possible to test the allogeneic cell preparations of various origin in humans: from bone marrow (NCT01860417) [74], from the adult precursors of the mesenchymal cells (NCT01290367) [75] and from the juvenile chondrocytes (NCT01771471) [76].

The stromal cells of adipose-derived tissue (ADSCs) are worth attention in the matter of elaboration of cell preparations. Considering the accessibility and possibility of getting maximally sufficient amount of cells as well as experimentally proved (in animals) capacity for function renewal in NP cells, the ADSCs are very promising to be used in clinic [77, 78].

The data of experimental investigations show that their implantation into canine IVD after removing of hernia sequester promotes its regeneration, as it is evidenced from unchanged morphology and MRI maintenance of the disc height [79].

Other investigators have shown that co-culture of ADSCs with NP cells suppresses apoptosis by suppressing activation of caspase- 9 and caspase-3. Moreover, the ADSCs protect NP cells from the destroying action of compression owing to the considerable expression of the proteins of the extracellular matrix protein genes (SOX9, COL2A1 and ACAN), genes (TIMP-1 and TIMP-2) of metalloproteinase tissue inhibitors (TIMPs) and cytokeratin 8 (CK8). Also, the ADSCs inhibited anti-inflammatory factors IL-1 $\beta$, IL-6, TGF- $\beta 1$ and TNF- $\alpha$ [78].

In January 2015, in view of the positive results obtained in experimental animals, the clinical trial (phase I) of autologous adipose tissue-derived stem cells in combination with the hyaluronic acid derivatives was started «Autologous Adipose Derived Stem Cell Therapy for Intervertebral Disc Degeneration» (NCT02338271) involving 10 patients with chronic low back pain and degenerated lumbar IVDs [80]. 


\section{CONCLUSION}

To sum up, the application of cell therapy at degenerative-dystrophic diseases of the locomotor apparatus and intervertebral disc hernias in particular is effective and promising. Implantation of cell prevents loss of disc height compared with control group patients, who underwent the removal of hernia sequester only without further transplantation. Both, the experimental investigations in animals and the following clinical trials evidence the improvement of biochemical properties of the spine and pain weakening/loss. Importantly, the safety of biological material considering the need for manipulations in vitro remains in the focus of thorough attention. The future large-scale randomized trials will ascertain a real safety and effectiveness of cell therapy in the intervertebral disc regeneration.

1. Katz JN. Lumbar disc disorders and low-back pain: socioeconomic factors and consequences. J Bone Joint Surg Am. 2006; 88(2):21-24.

2. Vos T, Flaxman AD, Naghavi M, et al. Years lived with disability (YLDs) for 1160 sequelae of 289 diseases and injuries 1990-2010: a systematic analysis for the Global Burden of Disease Study 2010. The Lancet. 2010; 380(9859):2163-2196.

3. Dagenais $S$, Tricco A, Haldeman $S$. Synthesis of recommendations for the assessment and management of low back pain from recent clinical practice guidelines. Spine Journal. 2010; 10(6):514-529.

4. Shamji MF, Setton $L A$, Jarvis $V$, et al. Proinflammatory cytokine expression profile in degenerated and herniated human intervertebral disc tissues. Arthritis Rheum. 2010; 62:1974-1982.

5. Risbud MV, Shapiro IM. Role of Cytokines in Intervertebral Disc Degeneration: Pain and Disc-content. Nat Rev Rheumatol. 2014; 10(1):44-56.

6. Molinos M, Almeida CR, Caldeira J, et al. Inflammation in intervertebral disc degeneration and regeneration. J. R. Soc. 2015; 12: 20141191.

7. Melrose J, Roberts $S$, Smith $S$, et al. Increased nerve and blood vessel ingrowth associated with proteoglycan depletion in an ovine anular lesion model of experimental disc degeneration. Spine. 2002; 27:1278-1285.

8. Freemont AJ, Watkins A, Le Maitre C, et al. Nerve growth factor expression and innervation of the painful intervertebral disc. J Pathol. $2002 ; 197: 286-292$.

9. Atlas SJ, Keller RB, Wu YA, et al. Long-term outcomes of surgical and nonsurgical management of sciatica secondary to a lumbar disc herniation: 10 year results from the maine lumbar spine study. Spine. 2005; 30(8):927-935.

10. Choy DS. Familial incidence of intervertebral disc herniation: an hypothesis suggesting that laminectomy and discectomy may be counterproductive. J Clin Laser Med Surg. 2000; 18(1):29-32.

11. Hakkinen A, Kiviranta I, Neva MH, et al. Reoperations after first lumbar disc herniation surgery; a special interest on residives during a 5-year follow-up. BMC Musculoskelet Disord. 2007; 8(2):DOI:10.1186/1471-2474-8-2.

12. Swartz KR, Trost GR. Recurrent lumbar disc herniation. Neurosurg Focus. 2003; 15(3):P. E10.

13. Xia XP, Chen HL, Cheng HB. Prevalence of adjacent segment degeneration after spine surgery: a systematic review and meta-analysis. Spine. 2013 ; $38: 597-608$.

14. Mochida J, Nishimura K, Nomura T, et al. The importance of preserving disc structure in surgical approaches to lumbar disc herniation. Spine. $1996 ; 21: 1556-1563$.

15. Schlegel JD, Smith JA, Schleusener RL. Lumbar motion segment pathology adjacent to thoracolumbar, lumbar, and lumbosacral fusions. Spine. $1996 ; 21: 970-981$.

16. Wei $A$, Shen B, Williams $L$, et al. Mesenchymal stem cells: potential application in intervertebral disc regeneration. Translational Pediatrics. 2014; 3(2):71-90.

17. Bach FC, Willems N, Penning LC, et al. Potential regenerative treatment strategies for intervertebral disc degeneration in dogs. BMC Vet Res. 2014; 10(1):3.

18. Gilbert HT, Hoyland JA, Richardson SM. Stem cell regeneration of degenerated intervertebral discs: current status (update). Curr Pain Headache Rep. 2013 ; 17:377.

19. Gilchrist CL, Francisco AT, Plopper GE. Nucleus pulposus cell-matrix interactions with laminins. Eur Cell Mater. 2011; 21:523-532.

20. Hardingham TE, Muir H. The specific interaction of hyaluronic acid with cartilage proteoglycans. Biochim Biophys Acta. 1972; 279:401-405.

21. Antoniou J, Steffen T, Nelson F, et al. «The human lumbar intervertebral disc: Evidence for changes in the biosynthesis and denaturation of the extracellular matrix with growth, maturation, ageing, and degeneration». Journal of Clinical Investigation. 1996; 98(4):996-1003.

22. Adams MA, Hutton WC. Gradual disc prolapse. Spine.1985; 10(6):524-31.

23. Bach FC, de Vries HSA, Krouwels $A$. The species-specific regenerative effects of notochordal cell-conditioned medium on chondrocyte-like cells derived from degenerated human intervertebral discs. European Cells and Materials. 2015; 30:132-147.

24. Liebscher T, Haefeli M, Wuertz K, et al. Age-related variation in cell density of human lumbar inter- vertebral disc. Spine. 2011; 36:153-159.

25. Hunter CJ, Matyas JR, Duncan NA. The notochordal cell in the nucleus pulposus: a review in the context of tissue engineering. Tissue Eng. $2003 ; \mathbf{9 : 6 6 7 - 6 7 7 . ~}$

26. Choi KS, Cohn MJ, Harfe BD. Identification of nucleus pulposus precursor cells and notochordal remnants in the mouse: implications for disk degeneration and chordoma formation. Dev Dyn. 2008; 237:3953-3958.

27. Sivakamasundari V, Lufkin T. Stemming the Degeneration: IVD Stem Cells and Stem Cell Regenerative Therapy for Degenerative Disc Disease. Advances in Stem Cells. 2013; 2013:ID 724547 .

28. Risbud MV, Shapiro I M. Notochordal Cells in the Adult Intervertebral Disc: New Perspective on an Old Question. Eukaryot Gene Expr. 2011; 21(1):29-41.

29. Pattappa G, Li Z, Peroglio M, et al. Diversity of intervertebral disc cells: phenotype and function. J. Anat. 2012; 221:480-496.

30. Walmsley $R$. The development and growth of the intervertebral disc. Edinburgh Med J. 1953; 60(8):341-364.

31. Roberts S, Evans H, Trivedi J, et al. Histology and pathology of the human intervertebral disc. J Bone Joint Surg. 2006; 88(2):10-14.

32. Hunter CJ, Matyas J R, Duncan NA. Cytomorphology of notochordal and chondrocytic cells from the nucleus pulposus: a species comparison. J Anat. 2004; 205:357-362.

33. Deduch NV. Mezhpozvonkovye diski: strukturnaja organizacija v norme i pri patologii [Intervertebral discs: structural organization in health and disease]. Problemy osteologii - Prorblems of osteology, 2008; 11(3-4):11-17.

34. Bron JL, Helder MN, Meisel H-J, et al. Repair, regenerative and supportive therapies of the annulus fibrosus: achievements and challenges. Eur Spine J. 2009; 18:301-313. 
35. Tomaszewski KA, Walocha JA, Mizia E, et al. Age- and degeneration-related variations in cell density and glycosaminoglycan content in the human cervical intervertebral disc and its endplates. Pol J Pathol. 2015; 66(3):296-300.

36. Risbud MV, Guttapalli A, Tsai TT, et al. Evidence for skeletal progenitor cells in the degenerate human intervertebral disc. Spine. 2007; 32(23): 2537-2544.

37. Roberts S, Menage J, Urban JP. Biochemical and structural properties of the cartilage end-plate and its relation to the intervertebral disc. Spine. $1989 ; 14: 166-174$.

38. Adams M A, Roughley PJ. What is Intervertebral Disc Degeneration, and What Causes It? Spine. 2006; 31(18):2151-2161.

39. Brisby $\mathrm{H}$, Papadimitriou N, Brantsing $\mathrm{C}$, et al. The presence of local mesenchymal progenitor cells in human degenerated intervertebral discs and possibilities to influence these in vitro: a descriptive study in humans. Stem Cells Dev. 2013; 22:804-14.

40. Kim KW, Ha KY, Lee JS, et al. Notochordal cells stimulate migration of cartilage end plate chondrocytes of the intervertebral disc in in vitro cell migration assays. Spine J. 2009; 9:323-9.

41. Martin JT, Milby AH, Chiaro JA, et al. Translation of an Engineered Nanofibrous Disc-like Angle Ply Structure for Intervertebral Disc Replacement in a Small Animal Model. Acta Biomater. 2014; 10(6):2473-2481.

42. Crevensten G, Walsh AJ, Ananthakrishnan D, et al. Intervertebral disc cell therapy for regeneration: mesenchymal stem cell implantation in rat intervertebral discs. Ann. Biomed. Eng. 2004; 32:430-434.

43. Wang YH, Yang B, Li WL, Li J. M. Effect of the mixture of bone marrow mesenchymal stromal cells and annulus fibrosus cells in repairing the degenerative discs of rabbits. Genet Mol Res. 2015; 14(1):2365-73.

44. Winkelstein BA, Allen KD, Setton LA. Intervertebral Disc Herniation: Pathophysiology and Emerging Therapies. The Intervertebral Disc. 2014; D0I 10.1007/978-37091-1535-0_19.

45. Henriksson HB, Svanvik T, Jonsson M , et al. Transplantation of human mesenchymal stems cells into intervertebral discs in a xenogeneic porcine model. Spine. 2009; 34:141-148.

46. Zhang $Y$, Drapeau $S$, Howard SA, et al. Transplantation of goat bone marrow stromal cells to the degenerating intervertebral disc in a goat disc injury model. Spine. 2011; 36:372-377.

47. Mizrahi 0, Sheyn D, Tawackoli W, et al. Nucleus pulposus degeneration alters properties of resident progenitor cells. The Spine Journal. $2013 ; \mathbf{1 3 ( 7 ) : 8 0 3 - 8 1 4 . ~}$

48. Gorensek M, Jaksimovic C, Kregar-Velikonja N. Nucleus pulposus repair with cultured autologous elastic cartilage derived chondrocytes. Cell. Mol. Biol. Lett. 2004; 9:363-373.

49. Kroeber MW, Unglaub F, Wang H, et al. New in vivo animal model to create intervertebral disc degeneration and to investigate the effects of therapeutic strategies to stimulate disc regeneration. Spine. 2002; 27:2684-2690.

50. Brinckerhoff CE, Martrisian LM. Matrix metalloproteinases: a tail of a frog that became a prince. Nat Rev Mol Cell Biol. $2002 ; 3: 207-214$.

51. Moskowitz RW, Ziv I, Denko CW, et al. Spondylosis in sand rats: a model of intervertebral disc degeneration and hyperostosis. J Orthop Res. $1990 ; \mathbf{8 : 4 0 1 - 4 1 1 . ~}$

52. Bergknut N. Intervertebral Disc Degeneration in Dogs. Doctoral Thesis Swedish University of Agricultural Sciences Utrecht University Uppsala \& Utrecht. 2011 ; $p 111$.

53. Hansen HJ. A pathologic-anatomical interpretation of disc degeneration in dogs. Acta Orthop Scand. 1951; 20:280-293.

54. Webb A. Potential sources of neck and back pain in clinical conditions of dogs and cats: a review. Vet J. 2003; $165(3): 193-213$.

55. Xin $H$, Zhang $C$, Wang $D$, et al. Tissue-engineered allograft intervertebral disc transplantation for the treatment of degenerative disc disease: experimental study in a beagle model. Tissue Eng Part A. 2013; 19(1-2):143-51.

56. Hohaus C, Ganey TM, Minkus Y, et al. Cell transplantation in lumbar spine disc degeneration disease. Eur Spine J. 2008; 17(4):492-503.

57. Lehmann TP, Filipiak $K$, Juzwa $W$, et al. Co-culture of human nucleus pulposus cells with multipotent mesenchymal stromal cells from human bone marrow reveals formation of tunnelling nanotubes. Mol Med Rep. 2014; 9(2):574-82.

58. Strassburg S, Richardson SM, Freemont AJ, et al. Co-culture induces mesenchymal stem cell differentiation and modulation of the degenerate human nucleus pulposus cell phenotype. Regen Med. 2010; 5(5):701-11.

59. Richardson SM, Kalamegam G, Pushparaj PN, et al. Mesenchymal Stem Cells in Regenerative Medicine: Focus on Articular Cartilage and Intervertebral Disc Regeneration. A. Methods. 2015; S1046-2023(15):30091-8.

60. latridis $J C, N i c o l l S B$, Michalek $A J$, et al. Role of biomechanics in intervertebral disc degeneration and regenerative therapies: what needs repairing in the disc and what are promising biomaterials for its repair? Spine J. 2013; 13:243-62.

61. Zhang Z, Li F, Tian H, et al. Differentiation of adiposederived stem cells toward nucleus pulposus-like cells induced by hypoxia and a three-dimensional chitosanalginate gel scaffold in vitro. Chin Med J. 2014; 127:314-21.

62. Serigano K, Sakai D. Effect of cell number on mesenchymal stem cell transplantation in a canine disc degeneration model. J Orthop Res. $2010 ; \mathbf{2 8 ( 1 0 ) : 1 2 6 7 - 7 5 . ~}$

63. Carragee E, Cuellar JM, Hurwitz EL, et al. Does provocative discography cause clinically important injury to the lumbar intervertebral disc? a ten-year matched cohort stud. Spine J. 2011; 11(10):S23-S24.

64. Adams MA, Dolan P, Hutton WC. The stages of disc degeneration as revealed by discograms. J Bone Joint Surg Br. 1986; 68(1):36-41.

65. Gruber $H E$, Rhyne $A L$, Hansen $K J$, et al. Deleterious effects of discography radiocontrast solution on human annulus cell in vitro: changes in cell viability, proliferation, and apoptosis in exposed cells. Spine J. 2012; 12(4):329-335.

66. Martin JT, Gorth DJ, Beattie EE, et al. Needle puncture injury causes acute and long-term mechanical deficiency in a mouse model of intervertebral disc degeneration. J Orthop Res. 2013; 31(8):1276-82.

67. Le Maitre CL, Hoyland JA, Freemont AJ. Catabolic cytokine expression in degenerate and herniated human intervertebral discs: IL-1beta and TNFalpha expression proile. Arthritis Res Ther. 2007; 9:77.

68. Park J-B, Chang H, Kim KW. Expression of Fas ligand and apoptosis of disc cells in herniated lumbar disc tissue. Spine. 2001; 26:618-621.

69. Brisby $H$, Papadimitriou N, Brantsing $C$, et al. The presence of local mesenchymal progenitor cells in human degenerated intervertebral discs and possibilities to influence these in vitro: a descriptive study in humans. Stem Cells Dev. 2013; 22(5):804-14.

70. NOVOCART US National Library of Medicine. ClinicalTrials.gov [online], https://clinicaltrials.gov/ct2/show/ NCT01640457 (2014).

71. Orozco L, Soler $R$, Morera C, et al. Intervertebral disc repair by autologous mesenchymal bone marrow cells: a pilot study. Transplantation. 2011; 92(7):822-8.

72. Yoshikawa $T$, Ueda $Y$, Miyazaki K, et al. Disc regeneration therapy using marrow mesenchymal cell transplantation: a report of two case studies. Spine. 2010; 35:E475-E480.

73. Hufe SMW, Mark AR. Intradiscal injection of hematopoietic stem cells in an attempt to rejuvenate the intervertebral disc. Stem cell dev. 2006; 15:136-137.

74. US National Library of Medicine. ClinicalTrials.gov [online], https://clinicaltrials.gov/ct2/show/ NCT01860417 (2014).

75. US National Library of Medicine. ClinicalTrials.gov [online], https://clinicaltrials.gov/ct2/show/ NCT01290367 (2014). 
76. US National Library of Medicine. ClinicalTrials.gov [online], https://clinicaltrials.gov/ct2/show/ NCT01771471 (2014).

77. Xie LW, Fang $H$, Chen AM, et al. Differentiation of rat adipose tissue-derived mesenchymal stem cells towards a nucleus pulposus-like phenotype in vitro. Chin J Traumatol. 2009; 12(2):98-103.

78. Sun Z, Luo B, Liu Z-H, et al. Adipose-Derived Stromal Cells Protect Intervertebral Disc Cells in Compression: Implications for Stem Cell Regenerative Disc Therapy. Int J Biol Sci. 2015; 11(2):133-143.

79. Ganey T, Hutton CW, Moseley T, et al. Intervertebral Disc Repair Using Adipose Tissue-Derived Stem and Regenerative Cells Experiments in a Canine Model. Spine. 2009; 34(21):2297-2304.

80. US National Library of Medicine. ClinicalTrials.gov [online], https://clinicaltrials.gov/ct2/show/NCT02338271 (2015).

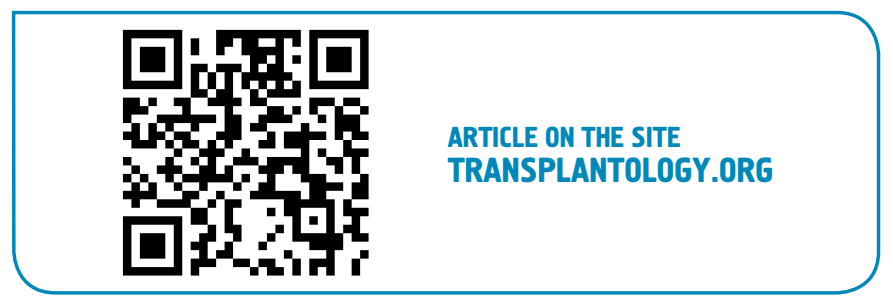

The author indicates no potential conflicts of interest.

Received: October 05, 2015

Accepted: November 09, 2015 